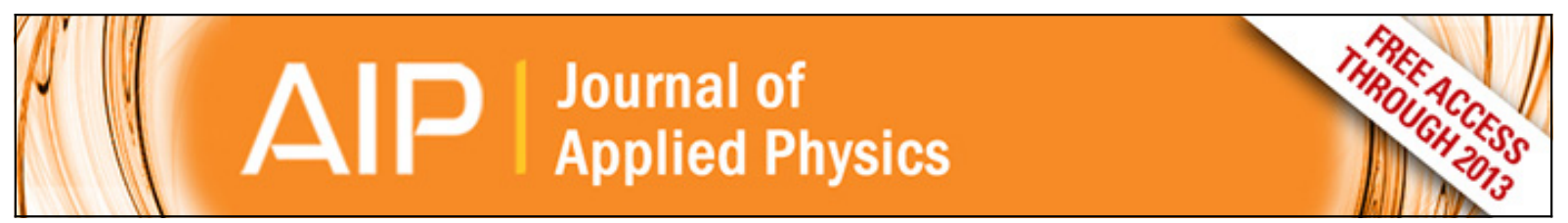

Electronic properties of doped magnesium thioindate ternary spinel in the normal and in the inverse structure

C. Tablero

Citation: Journal of Applied Physics 114, 033713 (2013); doi: 10.1063/1.4816102

View online: http://dx.doi.org/10.1063/1.4816102

View Table of Contents: http://scitation.aip.org/content/aip/journal/jap/114/3?ver=pdfcov

Published by the AIP Publishing

A AlP Re-register for Table of Content Alerts 


\title{
Electronic properties of doped magnesium thioindate ternary spinel in the normal and in the inverse structure
}

\author{
C. Tablero \\ Instituto de Energía Solar, E.T.S.I. de Telecomunicación, Universidad Politécnica de Madrid, \\ Ciudad Universitaria s/n, 28040 Madrid, Spain
}

(Received 18 April 2013; accepted 3 July 2013; published online 19 July 2013)

\begin{abstract}
We present a theoretical study of the structural and electronic properties of the M-doped $\operatorname{MgIn}_{2} \mathrm{~S}_{4}$ ternary spinel semiconductor with $\mathrm{M}=\mathrm{V}, \mathrm{Cr}$, and $\mathrm{Mn}$. All substitutions, in the normal and in the inverse structure, are analyzed. Some of these possible substitutions present intermediate-band states in the band gap with a different occupation for a spin component. It increases the possibilities of inter-band transitions and could be interesting for applications in optoelectronic devices. The contribution to, and the electronic configuration of, these intermediate bands for the octahedral and tetrahedral sites is analyzed and discussed. The study of the substitutional energies indicates that these substitutions are favorable. Comparison between the pure and doped host's absorption coefficients shows that this deeper band opens up more photon absorption channels and could therefore increase the solar-light absorption with respect to the host. (C) 2013 AIP Publishing LLC. [http://dx.doi.org/10.1063/1.4816102]
\end{abstract}

\section{INTRODUCTION}

The ternary spinels $\mathrm{AB}_{2} \mathrm{X}_{4}$ comprise an important class of ceramic compounds with a variety of interesting physical properties and with a wide range of potential applications in device technology. It is because of their electronic structure and the presence of three different chemical components which could allow the tailoring of some of the physical properties. A spineltype structure allows a variety of A and B cations of different size and charge. The two most common spinel types are 2-3 (with $2+$ and $3+$ cation oxidation stares) and 4-2 spinels.

The spinel structure belongs to the space group $O_{h}^{7}=F d 3 m$ and consists of an almost close-packed array of anions, with one eighth of the tetrahedral and one half of the octahedral interstices filled by cations. The distribution of the cations among the available sites may vary. In the normal distribution in a ternary spinel, $(\mathrm{A})\left[\mathrm{B}_{2}\right] \mathrm{X}_{4}$, the two B-cations are located in octahedral sites (square brackets) while the A-cations are in tetrahedral sites (parenthesis). In the inverse spinels, (B) $[\mathrm{AB}] \mathrm{X}_{4}$, the octahedral sites are occupied by both $\mathrm{A}$ - and $\mathrm{B}$-ions, while $\mathrm{B}$-ions are located in the tetrahedral sites. Intermediate distributions between these two extremes also are known. These may be characterized by specifying the fraction $\mathrm{x}$ of $\mathrm{B}$ ions in tetrahedral sites $\left(A_{1-x} B_{x}\right)\left[A_{x} B_{2-x}\right] X_{4}(0 \leq x \leq 1)$, where $x$ represents the degree of inversion: $\mathrm{x}=0$ corresponds to the normal spinel and $x=1$ to the inverse. The inverse and partially inverse structures locally have a lower symmetry than the direct one (point groups $D_{2 h}$ and $C_{3 v}$, respectively). In many spinels, the degree of inversion varies with temperature. ${ }^{1}$

In particular, the $\mathrm{MgIn}_{2} \mathrm{~S}_{4}$ spinel is an attractive material with a potential for many areas of fundamental and technological interest, such as magnetism, ferroelectricity, tunable optical lasers, ${ }^{2,3}$ and superconductivity. ${ }^{4}$ The primitive unit cell contains 2 formula units of $\mathrm{MgIn}_{2} \mathrm{~S}_{4}$ and is characterized by two structural parameters: the cubic lattice constant $a=10.709 \AA$ and the anion displacement parameter $u=0.382 .^{5}$
The properties can also be modified through the insertion of intermediate states into the energy bandgap. Depending on the occupation of these states, there are additional inter-band transitions that could potentiality improve these optoelectronic properties. For example, they could be considered as a promising candidate for photon absorbing materials in solar cell devices. ${ }^{6}$

It seems appropriate to analyze whether the insertion of intermediate states into the energy band gap using selected impurities improves the optoelectronic properties with respect to the host spinel. Thus, we explore the resulting electronic properties using the $\mathrm{V}, \mathrm{Cr}$, and $\mathrm{Mn}$ as possible impurities because they introduce intermediate states into the energy bandgap. All possible cation substitutions by these impurities in the normal and the inverse structures are considered. First, we describe the methodology. Then, the resulting states and the relative stability of the final compounds will be evaluated and analyzed. Finally, Sec. IV contains the main conclusions.

\section{CALCULATIONS}

In order to explore isolated defects (at least on the order of hundreds of atoms) we have used large supercells and Density Functional Theory (DFT). ${ }^{7}$ The calculations are affected by the well-known band gap underestimation characteristic of the Generalized Gradient Approximation (GGA)DFT method. In theory, the band gap underestimation problem may be avoided using many-body methods such as ExactExchange DFT, hybrid DFT, self-consistent Green function with screened interaction approximation (GW), quantum Monte Carlo calculations, etc. The main problem of these more sophisticated methods is that they are not practical for the large supercells required in point-defect studies. ${ }^{8,9}$ With small supercells and more sophisticated methods, the defect, instead of being surrounded by a large region of perfect host semiconductor is now surrounded by mirror images of itself. 
Due to this incorrectly high defect concentration, artificial interactions are introduced such as image charges, spurious electrostatic interactions, and spurious hybridization.

The standard Kohn-Sham ${ }^{10}$ equations have been solved self-consistently ${ }^{11}$ using the GGA in the form of Perdew, Burke, and Ernzerhof ${ }^{12}$ for the exchangecorrelation potential. The standard Troullier-Martins ${ }^{13}$ pseudopotential is adopted and expressed in the Kleinman-Bylander ${ }^{14}$ factorization. The Kohn-Sham orbitals are represented using a linear combination of confined pseudoatomic orbitals. ${ }^{15}$

In all of the results presented in this work, a double-zeta with polarization localized basis set has been used with periodic boundary conditions and 108, 18, and 6 special $k$ points in the irreducible Brillouin zone for a 14-, 112-, and 252-atom cell $\left(\mathrm{MgIn}_{2-\mathrm{y}} \mathrm{M}_{\mathrm{y}} \mathrm{S}_{4}\right.$ with $\mathrm{y}=0.57,0.071$ and 0.031 for 14-, 112-, and 252-atom cell, respectively). The bigger and the smaller supercells have only been used in a few cases in order to compare them with the 112 atom supercells.

The imaginary part of the dielectric function is directly related to the electronic band structure, in particular to the energies $\left(E_{\mu, \vec{k}}\right)$ and the occupations $\left(f_{\mu, \vec{k}}\right)$ of the $\mu$ bands. It can be computed by summing up all possible transitions from the occupied to the unoccupied states, taking into account the appropriate transition dipole matrix elements $p_{\mu \lambda}=\langle\mu, \vec{k}|\hat{p}| \lambda, \vec{k}\rangle$ between the states $|\mu, \vec{k}\rangle$ and $|\lambda, \vec{k}\rangle$ of the $\mu$ and the $\lambda$ bands at point $\vec{k}$ of the Brillouin zone

$$
e_{2}(E) \sim \frac{1}{E^{2}} \sum_{\vec{k}} \sum_{\mu} \sum_{\lambda}\left|p_{\mu \lambda}\right|^{2}\left[f_{\mu, \vec{k}}-f_{\lambda, \vec{k}}\right] \delta\left(E_{\lambda, \vec{k}}-E_{\mu, \vec{k}}-E\right) .
$$

The knowledge of the imaginary part of the dielectric function allows the calculation of others optical functions using the Kramers-Kronig relations.

A further extension beyond the GGA was carried out using the GGA + U method. ${ }^{16-18}$ An effective orbitaldependent one-electron potential and an effective Hubbard term $\mathrm{U}$ is included to improve the description of the manybody effect not treated adequately in the GGA approach. ${ }^{17,18}$ The value of $U$ depends on the choice of the orbitals on which the correction is applied, on the way the orbital occupations are computed, and on the GGA + $\mathrm{U}$ implementation chosen. ${ }^{17-20}$ In this work, we applied the orbital-dependent one-electron potential to the $d$-M states using the GGA/ local-density approximation (LDA) $+\mathrm{U}$ formalism described in Refs. 17 and 18.

\section{RESULTS AND DISCUSSION}

\section{A. Host spinel}

First, we have analyzed how the two structural parameters, lattice parameter $a$ and anion displacement parameter $u$, affects the electronic structure. The parameters calculated using the methodology described in the calculation section are $a=10.71 \AA$ and $u=0.381$. These values are close to the experimental: $a=10.709 \AA$ and $u=0.382$ (Ref. 5) and to other theoretical calculations $(a=10.52 \AA$ and $u=0.382$ (Ref. 21)). The energy difference between the energy gap calculated with these parameters $\left(E_{\mathrm{g}}=2.20 \mathrm{eV}\right)$ and those calculated with the experimental ones is lower than $0.01 \mathrm{eV}$, which is similar to the calculation precision. The energy bandgap is direct, in according with experimental results in the literature. ${ }^{22}$

In order to analyze the energy gap with the supercell size, we have obtained the gap using the experimental parameters for all supercells (from 14 to 252 atoms). In all cases, the energy gap for the normal structure is $2.20 \mathrm{eV}$. These results compare well with experimental $(2.14 \mathrm{eV}$ (Refs. 23 and 24]) and theoretical results in the literature using LDA/GGA approach and different basis sets (1.65 eV, ${ }^{25} 1.69-1.73 \mathrm{eV},{ }^{26} 1.77 \mathrm{eV},{ }^{27}$ and $2.4 \mathrm{eV}$ (Ref. 21)). Results with more sophisticated theoretical methods and lower 56- and 14-atom cells are: ${ }^{26} 2.10 \mathrm{eV}$ (using metaGGA functionals ${ }^{28}$ ), $2.84 \mathrm{eV}$ (with the screened hybrid functional of Heyd, Scuseria, and Ernzerhof $(\mathrm{HSE})^{29}$ ), and $3.85 \mathrm{eV}$ (with GW).

The bandgap for the inverse and partially inverse spinels are smaller than those of the normal spinels $(1.40 \mathrm{eV}$ for $\mathrm{x}=1$ and $1.11 \mathrm{eV}$ for $\mathrm{x}=0.5$ ). This is because the local symmetry in the inverse structure is lower than the normal structure. It causes further level repulsion within the VB and within the conduction band (CB), pushing up the VB maximum and pushing down the $\mathrm{CB}$ minimum states, thus lowering the bandgap, similar to that observed in semiconductor alloys. ${ }^{30}$ Thus, in principle, one can control the bandgap by controlling the cation inversion parameter $x$. From our results the normal structure is the most stable, and the inverse structure is more stable than the partial inverse structure with $\mathrm{x}=0.5$. It coincides with other results in the literature. ${ }^{21}$

For the 14-atom primitive cell with two $\mathrm{MgIn}_{2} \mathrm{~S}_{4}$ units, there are two tetrahedral sites and four octahedral sites. Thus, for the normal structure $(\mathrm{Mg})\left[\mathrm{In}_{2}\right] \mathrm{S}_{4}$, there is only one possibility for the arrangements of the atoms. However, for the completely inverse cell (In) $[\mathrm{MgIn}] \mathrm{S}_{4}$, there are six different degenerated arrangements of two Mg and In atoms on four octahedral sites. In supercells, larger than the primitive cell, the number of possible configurations for a given $x \neq 0$ increases very quickly with the size of the supercell, except for the normal structure $(x=0)$, for which there is a single configuration. Therefore, for a degree of inversion $x \neq 0$ there are many possible configurations, in general, with different energy and different energy band gaps. This can be the reason for the large dispersion of experimental and theoretical band gap values even when samples with the same degree of inversion are compared.

\section{B. Doped-spinel}

When host atoms are substituted by an impurity $\mathrm{M}$ the distribution of this impurity among the available sites may vary. In the normal structure $(\mathrm{x}=0)$, i.e., $(\mathrm{Mg})\left[\mathrm{In}_{2}\right] \mathrm{S}_{4}$, the general formula for the $\mathrm{M}_{\mathrm{Mg}}$ and $\mathrm{M}_{\mathrm{In}}$ substitutions are $\left(\mathrm{Mg}_{1-\mathrm{y}} \mathrm{M}_{\mathrm{y}}\right)\left[\mathrm{In}_{2}\right] \mathrm{S}_{4}$ and $(\mathrm{Mg})\left[\mathrm{In}_{2-\mathrm{y}} \mathrm{M}_{\mathrm{y}}\right] \mathrm{S}_{4}$, respectively, where $y$ indicates the impurity concentration. For the inverse structure, (In) $[\mathrm{MgIn}] \mathrm{S}_{4}$, the $\mathrm{M}_{\mathrm{Mg}}$ substitution corresponds to $\left(\mathrm{Mg}_{1-\mathrm{y}} \mathrm{M}_{\mathrm{y}}\right)\left[\mathrm{In}_{2}\right] \mathrm{S}_{4}$, i.e., $\mathrm{M}$ occupies a tetrahedral site. For the $\mathrm{M}_{\mathrm{In}}$ substitution in the inverse structure, $\mathrm{M}$ can occupy both sites: $\left(\operatorname{In}_{1-\mathrm{y}} \mathrm{M}_{\mathrm{y}}\right)[\mathrm{MgIn}] \mathrm{S}_{4}$ and $(\operatorname{In})\left[\mathrm{MgIn}_{1-\mathrm{y}} \mathrm{M}_{\mathrm{y}}\right] \mathrm{S}_{4}$. These 
five possibilities are analyzed in this work. In order to simplify the notation, we indicate the different substitutions between square brackets and parenthesis to indicate the octahedral or tetrahedral local symmetry of the site substitution, and a subindex to specify the degree of inversion. Then the five possible substitutions are: $\left[\mathrm{M}_{\mathrm{In}}\right]_{\mathrm{x}=0},\left(\mathrm{M}_{\mathrm{Mg}}\right)_{\mathrm{x}=0},\left[\mathrm{M}_{\mathrm{In}}\right]_{\mathrm{x}=1}$, $\left(\mathrm{M}_{\mathrm{In}}\right)_{\mathrm{x}=1}$, and $\left[\mathrm{M}_{\mathrm{Mg}}\right]_{\mathrm{x}=1}$, with $\mathrm{M}=\mathrm{V}, \mathrm{Cr}$ and $\mathrm{Mn}$.

The band structure for the majority spin component of these substitutions is shown in Figures 1-3 (panels (a)-(e)). The majority spin component presents intermediate states in the energy bandgap. The band structures for the minority spin components are similar both between themselves, and to the band structure of the host semiconductor. Particularly interesting cases are the $\left(\mathrm{Cr}_{\mathrm{Mg}}\right)_{\mathrm{x}=0},\left(\mathrm{~V}_{\mathrm{Mg}}\right)_{\mathrm{x}=0}$, and $\left[\mathrm{Mn}_{\mathrm{In}}\right]_{\mathrm{x}=0}$ substitutions with a partially full intermediate band (IB) isolated from the VB and CB. These compounds could have applications in high-efficiency solar cells. In addition to the VB-CB host semiconductor optical transition, the VB-IB and IB-CB transitions generate extra carriers. Thus, the current that could be extracted from this device will be larger than the host semiconductor. It increases the efficiency with respect to the host semiconductor. For the $\left(\mathrm{Cr}_{\mathrm{Mg}}\right)_{\mathrm{x}=0}$ substitution there is a full lower $t$ band and an empty upper $t$ band separated by an very small gap. Although this case is less favorable than when there is a partially full IB, it could also be interesting for solar cell or optoelectronic devices.

Other interesting cases are the $\left(\mathrm{Cr}_{\mathrm{Mg}}\right)_{\mathrm{X}=1}$ and $\left[\mathrm{Mn}_{\mathrm{In}}\right]_{\mathrm{x}=1}$ with a partially full band that overlaps with the $\mathrm{CB}$ and $\mathrm{VB}$, respectively. It is well-known that GGA-DFT underestimates the band gaps. Therefore, with more accurate first-principles approaches ${ }^{31-34}$ that avoid the band-gap problem (Green function with screened interaction approximation, hybrid functionals, self-interaction-corrected density-functional theory, exact exchange method, etc.) these partially full bands could not overlap with the VB and/or the CB. The problem of these methods is the computational cost making their application impractical for the large supercells used in this work.

Using the ionic model, for the $\mathrm{M}_{\mathrm{Mg}}$ or $\mathrm{M}_{\mathrm{In}}$ substitutions two or three of the $\mathrm{M}$ electrons are given to the bonds, thus forming an impurity level with an oxidation state +2 or +3 : $\mathrm{V}^{2+}\left(\mathrm{d}^{3}\right)$ or $\mathrm{V}^{3+}\left(\mathrm{d}^{2}\right), \mathrm{Cr}^{2+}\left(\mathrm{d}^{4}\right)$ or $\mathrm{Cr}^{3+}\left(\mathrm{d}^{3}\right)$, and $\mathrm{Mn}^{2+}\left(\mathrm{d}^{5}\right)$ or $\mathrm{Mn}^{3+}\left(\mathrm{d}^{4}\right)$. The fivefold degenerated $d$ states of $\mathrm{M}$ are split by the crystalline field in the octahedral or tetrahedral sites into $d_{e}$ states with $e$ symmetry $\left(d_{z^{2}}\right.$ and $\left.d_{x^{2}-y^{2}}\right)$ and $d_{t}$ states with $t$ symmetry $\left(d_{x y}, d_{x z}\right.$, and $\left.d_{y z}\right)$. The crystal wavefunctions with $t$ and $e$ symmetry are formed mainly by the combination of the $d$-M states $\left(d_{t}\right.$ or $\left.d_{e}\right)$ and the host states with the appropriate symmetry $\left(h_{t}\right.$ or $\left.h_{e}\right): t \simeq \alpha_{t} \cdot d_{t}+\beta_{t} \cdot h_{t}$ and $e \simeq \alpha_{e} \cdot d_{e}+\beta_{e} \cdot h_{e}$. Additionally, these states are split into spin-up (+) and spin-down (-) components. In general, for the octahedral (tetrahedral) sites the $t_{+}\left(e_{+}\right)$band is in the $\mathrm{VB}$, and the states in the energy band gap are the $e_{+}\left(t_{+}\right)$. The $t_{-}$and $e_{-}$crystalline states contribute mainly to the CB. For the analyzed substitutions $\left[\mathrm{M}_{\mathrm{In}}\right]_{\mathrm{x}=0},\left[\mathrm{M}_{\mathrm{In}}\right]_{\mathrm{x}=1},\left[\mathrm{M}_{\mathrm{Mg}}\right]_{\mathrm{x}=1}$, $\left(\mathrm{M}_{\mathrm{Mg}}\right)_{\mathrm{x}=0}$, and $\left(\mathrm{M}_{\mathrm{In}}\right)_{\mathrm{x}=1}$ the band configurations are $t_{+}^{3} e_{+}^{0}$, $t_{+}^{3} e_{+}^{0}, t_{+}^{3} e_{+}^{1}, e_{+}^{2} t_{+}^{2}$, and $e_{+}^{2} t_{+}^{1}$ for $\mathrm{M}=\mathrm{Cr} ; t_{+}^{2} e_{+}^{0}, t_{+}^{2} e_{+}^{0}, t_{+}^{3} e_{+}^{0}$, $e_{+}^{2} t_{+}^{1}$, and $e_{+}^{2} t_{+}^{0}$ for $\mathrm{M}=\mathrm{V}$; and $t_{+}^{3} e_{+}^{1}, t_{+}^{3} e_{+}^{1}, t_{+}^{3} e_{+}^{2}, e_{+}^{2} t_{+}^{3}$, and $e_{+}^{2} t_{+}^{2}$ for $\mathrm{M}=\mathrm{Mn}$.
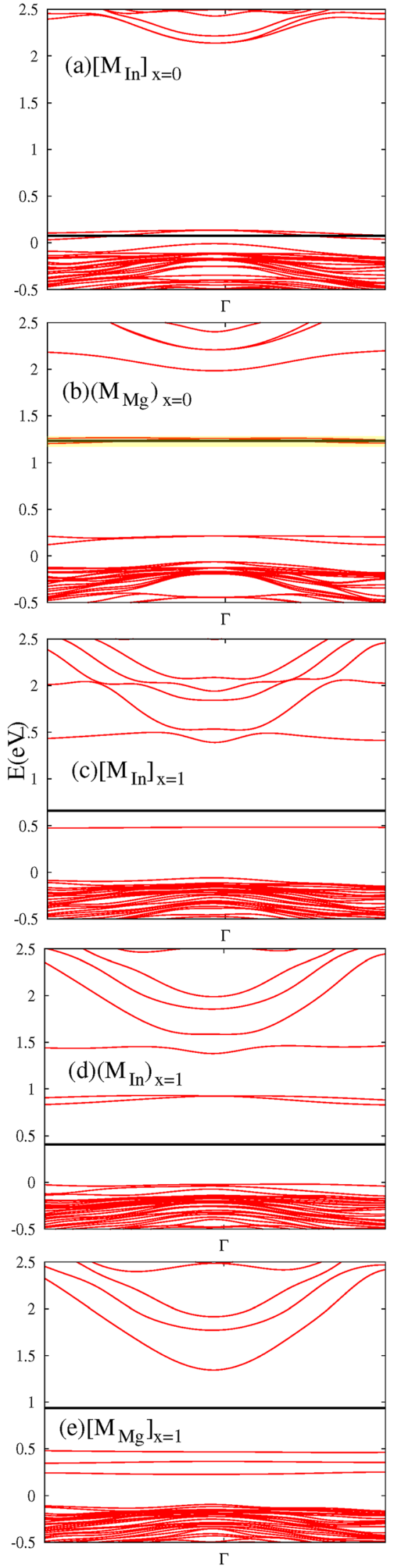

FIG. 1. Energy-band diagram for the (a) $\left[\mathrm{M}_{\mathrm{In}}\right]_{\mathrm{x}=0}$, (b) $\left(\mathrm{M}_{\mathrm{Mg}}\right)_{\mathrm{x}=0}$, (c) $\left[\mathrm{M}_{\mathrm{In}}\right]_{\mathrm{x}=1}$, (d) $\left(\mathrm{M}_{\mathrm{In}}\right)_{\mathrm{x}=1}$, and (e) $\left[\mathrm{M}_{\mathrm{Mg}}\right]_{\mathrm{x}=1}$ substitutions around the $\Gamma$ point in the $\mathrm{BZ}$ with $\mathrm{M}=\mathrm{V}$. The square brackets (parenthesis) correspond to the octahedral (tetrahedral) substitution sites. The VB edge of the $\mathrm{MgIn}_{2} \mathrm{~S}_{4}$ host spinel has been chosen as the energy origin. The horizontal lines in the panels (a)-(e) are the Fermi energy for each substitution. 

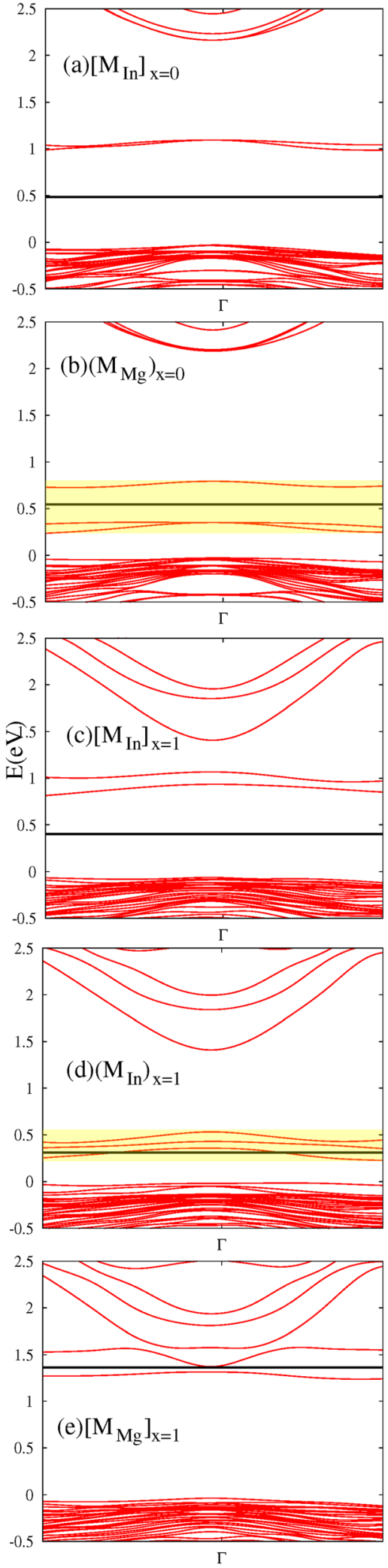

FIG. 2. Same legend as in Figure 1, but for $\mathrm{M}=\mathrm{Cr}$.

The previously discussed more interesting cases correspond to: $\left(\mathrm{Cr}_{\mathrm{Mg}}\right)_{\mathrm{x}=0}\left(e_{+}^{2} t_{+}^{2}\right),\left(\mathrm{Cr}_{\mathrm{In}}\right)_{\mathrm{x}=1}\left(e_{+}^{2} t_{+}^{1}\right),\left(\mathrm{V}_{\mathrm{Mg}}\right)_{\mathrm{x}=0}$ $\left(e_{+}^{2} t_{+}^{1}\right), \quad\left[\mathrm{Mn}_{\mathrm{In}}\right]_{\mathrm{x}=0} \quad\left(t_{+}^{3} e_{+}^{1}\right), \quad\left[\mathrm{Mn}_{\mathrm{In}}\right]_{\mathrm{x}=1} \quad\left(t_{+}^{3} e_{+}^{1}\right) . \quad$ For $\mathrm{Cr}$ and $\mathrm{V}$ the partially full IBs are $t$, whereas for the $\mathrm{Mn}$ are $e$.
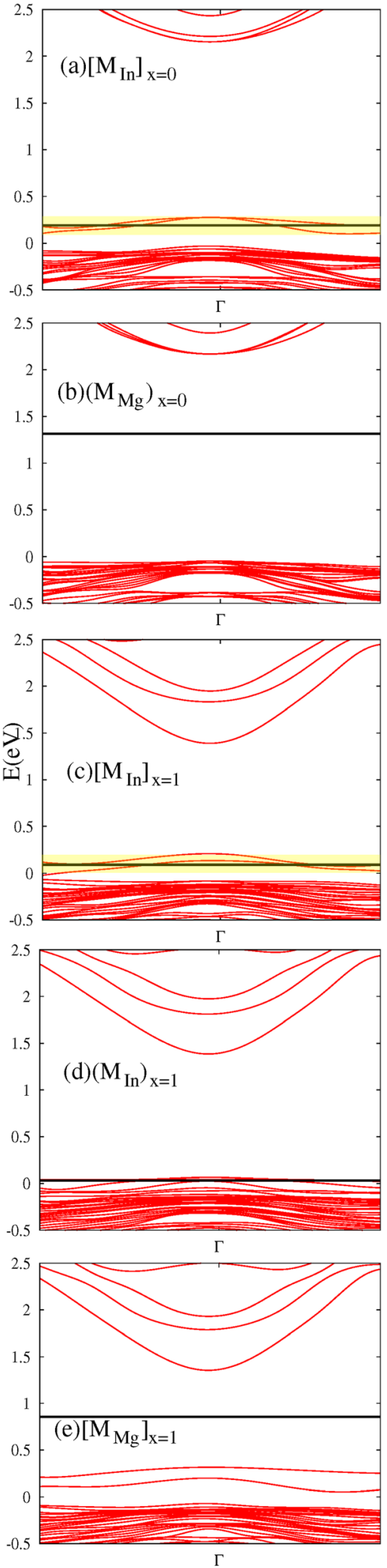

FIG. 3. Same legend as in Figure 1, but for $\mathrm{M}=\mathrm{Mn}$.

These conclusions are confirmed from both the band structure and the projected density-of-states analyses. In our analyses, we have considered that the substitutional sites have tetrahedral or octahedral local symmetry. However, the total symmetry is tetrahedral or octahedral distorted. Because of this the $d_{t}$ or $d_{e}$ states are slightly split. 
The $\mathrm{M}_{\mathrm{Mg}}$ substitution energy from the host spinel with inversion degree $x$ can be obtained as $\Delta \mathrm{E}_{\mathrm{x}}=\mathrm{E}\left[\mathrm{M}_{\mathrm{y}} \mathrm{Mg}_{1-\mathrm{y}} \mathrm{In}_{2} \mathrm{~S}_{4}\right]$ $-\mathrm{E}\left[\mathrm{MgIn}_{2} \mathrm{~S}_{4}\right]_{\mathrm{x}}+\mathrm{y}\left(\mathrm{E}_{\mathrm{Cd}}-\mathrm{E}_{\mathrm{M}}\right)$, where $\mathrm{E}\left[\mathrm{M}_{\mathrm{y}} \mathrm{Cd}_{1-\mathrm{y}} \mathrm{In}_{2} \mathrm{~S}_{4}\right]$ and $\mathrm{E}\left[\mathrm{CdI}{ }_{2} \mathrm{~S}_{4}\right]_{\mathrm{x}}$ are the total energies of the doped- and host-spinel, $y$ indicates the impurity concentration, and $\mathrm{E}_{\mathrm{Cd}}$ and $\mathrm{E}_{\mathrm{M}}$ are the energies of the elemental $\mathrm{Cd}$ and $\mathrm{M}$ atoms. For the $\mathrm{M}_{\mathrm{In}}$ substitution, it is necessary to change $\mathrm{M}_{\mathrm{y}} \mathrm{Mg}_{1-\mathrm{y}} \mathrm{In}_{2} \mathrm{~S}_{4}$ and $\mathrm{Mg}$ by $\mathrm{MgIn}_{2-\mathrm{y}} \mathrm{M}_{\mathrm{y}} \mathrm{S}_{4}$ and In, respectively. This substitution energy may be representative of the relative energy balance expected for the growth processes that use gaseous phases rather than solids for the deposition of the modified compound, like molecular beam epitaxy or physical vapor deposition. The values for the 112 atoms supercell $(\mathrm{y}=0.0625)$ are represented in Figure 4.

For all substitutions, $\Delta \mathrm{E}_{\mathrm{x}}$ is negative, indicating that thermodynamically the substitutions are favorable. The most favorable substitutions are for $\mathrm{Mn}, \mathrm{Cr}$, and $\mathrm{V}$, in accordance with the descending order of covalent radii. The octahedral substitutions are also more probable than the tetrahedral substitutions.

Because of the IB within the energy bandgap is full isolated from the VB and the CB for the $\left(\mathrm{Cr}_{\mathrm{Mg}}\right)_{\mathrm{x}=0},\left(\mathrm{~V}_{\mathrm{Mg}}\right)_{\mathrm{x}=0}$, $\left[\mathrm{Mn}_{\text {In }}\right]_{\mathrm{x}=0},\left(\mathrm{Cr}_{\mathrm{In}}\right)_{\mathrm{x}=1}$, and $\left[\mathrm{Mn}_{\mathrm{In}}\right]_{\mathrm{x}=1}$ substitutions, there is the possibility of photons with lower energy than the host semiconductor are absorbed. In the single-gap host semiconductor, only the VB-CB transition is possible. However, with a partially full IB, transition VB-IB and IB-CB with lower
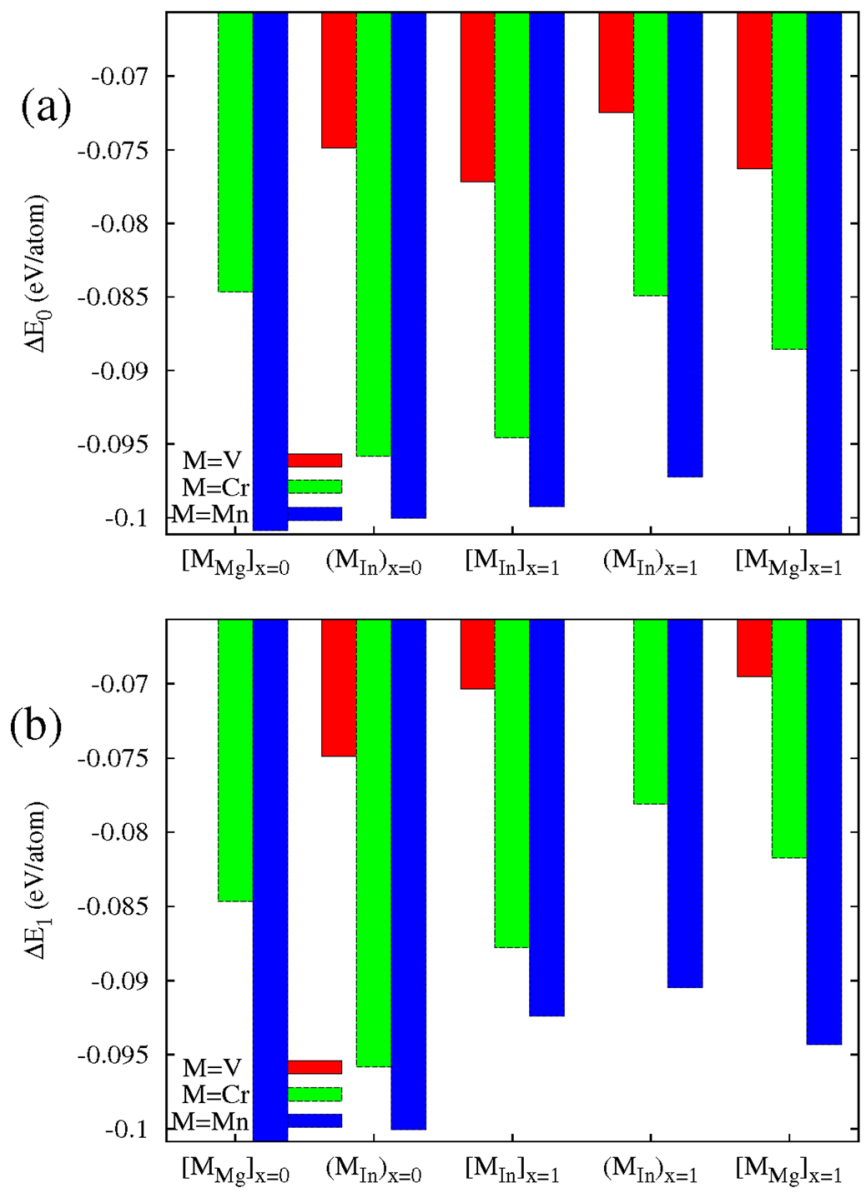

FIG. 4. Substitution energy from the (a) normal $\left(\Delta \mathrm{E}_{1}\right)$ and (b) inverse $\left(\Delta \mathrm{E}_{2}\right)$ host spinel. energy are possible. This can be seen in Figure 5, which shows the absorption coefficient broken down into the VB$\mathrm{CB}$, VB-IB, IB-CB, and IB-IB transitions for the majority spin component $(+)$ in the normal structures.

These sub-bandgap absorptions increase the mobile carriers (electrons in the $\mathrm{CB}$ and holes in the $\mathrm{VB}$ ) with respect to the single-gap host semiconductor. This implies a larger efficiency when these types of compounds are used to absorb the solar radiation in solar cells. ${ }^{6}$ In addition, these properties
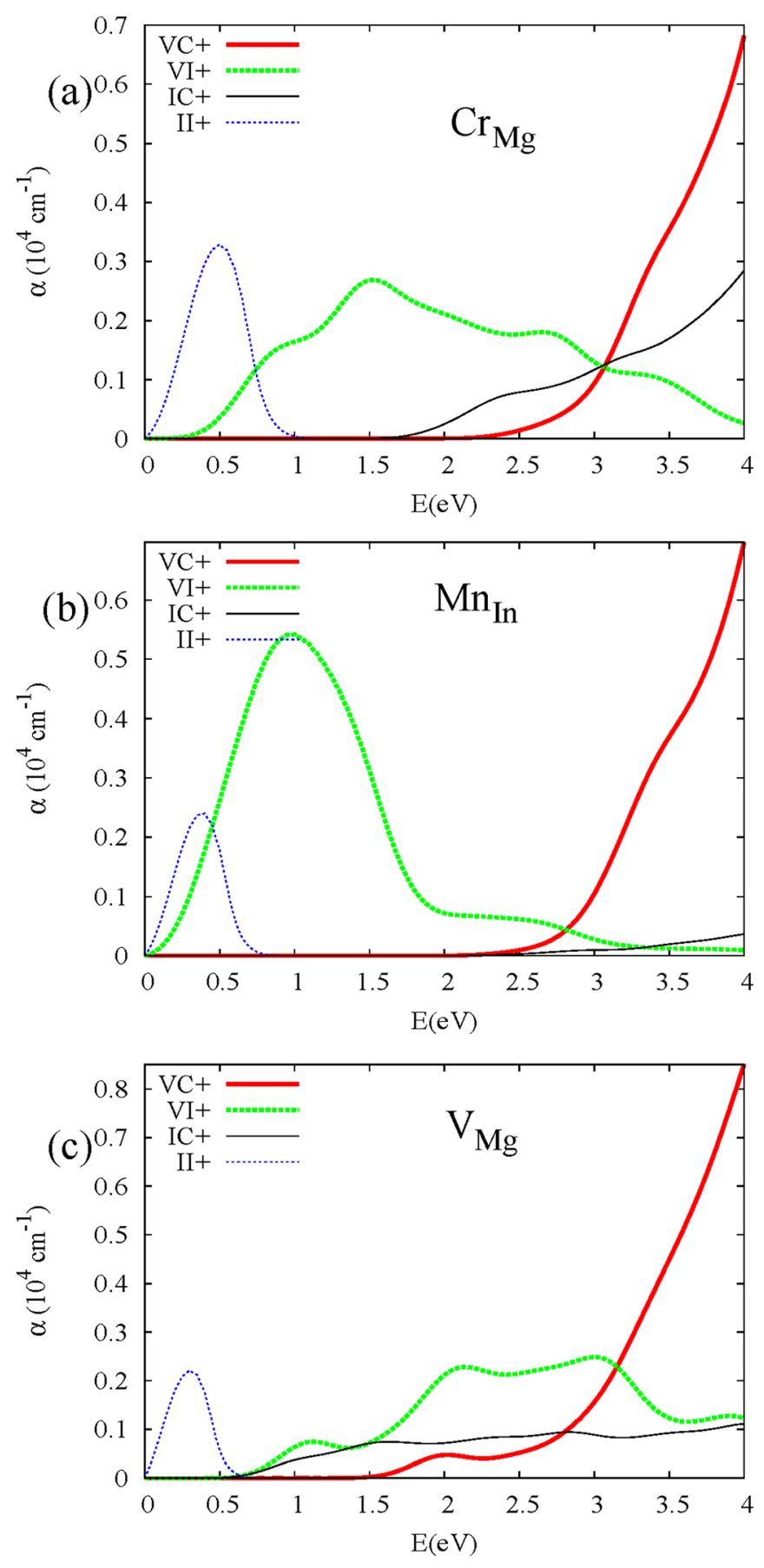

FIG. 5. Absorption coefficients $\alpha(E)$ for the majority spin component $(+)$ split in their components: VI + (between VB and IB), VC+ (between VB and $\mathrm{CB}$ ), IC+ (between IB and $\mathrm{CB}$ ), and II+ (inside the IB) of the (a) $\left(\mathrm{Cr}_{\mathrm{Mg}}\right)_{\mathrm{x}=0}$, (b) $\left[\mathrm{Mn}_{\mathrm{In}}\right]_{\mathrm{x}=0}$, and (c) $\left(\mathrm{V}_{\mathrm{Mg}}\right)_{\mathrm{x}=0}$ substitutions in the $\mathrm{MgIn}_{2} \mathrm{~S}_{4}$ structure. 
could also be interesting for other optoelectronic or spintronic devices.

The band model approximation breaks down for narrow bands. The local correlation effects could be very important
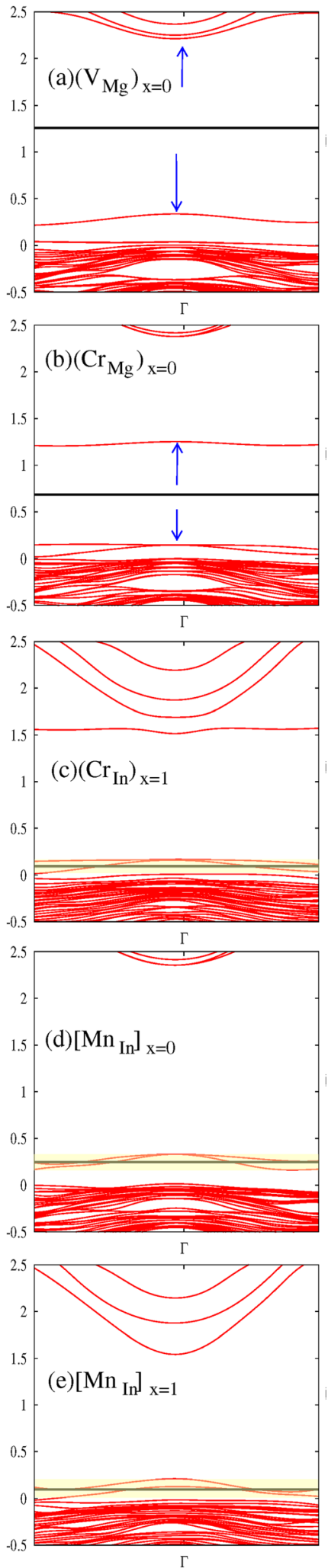

FIG. 6. GGA + U energy-band diagram for the (a) $\left(\mathrm{V}_{\mathrm{Mg}}\right)_{\mathrm{x}=0}$, (b) $\left(\mathrm{Cr}_{\mathrm{Mg}}\right)_{\mathrm{x}=0}$, (c) $\left(\mathrm{Cr}_{\mathrm{In}}\right)_{\mathrm{x}=1}$, (d) $\left[\mathrm{Mn}_{\mathrm{In}}\right]_{\mathrm{x}=0}$, and (e) $\left[\mathrm{Mn}_{\mathrm{In}}\right]_{\mathrm{x}=1}$ around the $\Gamma$ point in the BZ with $\mathrm{M}=\mathrm{V}$. The square brackets (parenthesis) correspond to the octahedral (tetrahedral) substitution sites. The horizontal lines are the Fermi energy for each substitution. and could shift the states in the IB and split the occupied states from the empty states on an energy scale of the gap. In order to verify this fact, we apply a further extension beyond the GGA using the GGA $+\mathrm{U}$ method with $\mathrm{U}=5 \mathrm{eV}$ (Figure 6). The main effects of GGA $+\mathrm{U}$ with respect to GGA are: (i) the band gap increase slightly from $2.2 \mathrm{eV}$ to $2.4 \mathrm{eV}$ for the normal spinel; (ii) For the $\left(\mathrm{V}_{\mathrm{Mg}}\right)_{\mathrm{X}=0}$ and $\left(\mathrm{Cr}_{\mathrm{Mg}}\right)_{\mathrm{X}=0}$ substitutions the partially full IB with GGA is split into an empty upper and a full lower Hubbard band (Figures 6(a) and 6(b)); (iii) For the $\left(\mathrm{Cr}_{\mathrm{In}}\right)_{\mathrm{x}=1}$ substitutions the partially full IB with GGA is split into an empty upper and a partially full IB (Figure 6(c)); (iv) For the $\left[\mathrm{Mn}_{\mathrm{In}}\right]_{\mathrm{X}=0}$ and $\left[\mathrm{Mn}_{\mathrm{In}}\right]_{\mathrm{X}=1}$ substitutions, the partially full IB is not split (Figures 6(d) and $6(\mathrm{e})$ ). The splitting depends on the partially full IB width and on the contribution of the $d$-M states to the IB. ${ }^{17,18}$ For larger impurity concentration (small 14-atom cells), the partially-full IB is wider, and it is not split for the $\left(\mathrm{Cr}_{\mathrm{Mg}}\right)_{\mathrm{X}=0}$ substitution, but it is split for the $\left(\mathrm{V}_{\mathrm{Mg}}\right)_{\mathrm{x}=0}$ substitution. In this case, the partially full IB is split even with a lower $\mathrm{U}=2 \mathrm{eV}$.

\section{CONCLUSIONS}

We have presented a theoretical study of the electronic properties of the doped $\mathrm{MgIn}_{2} \mathrm{~S}_{4}$ spinel. We carried out an analysis of almost all substitutions of host atoms by $\mathrm{M}(=\mathrm{Cr}$, $\mathrm{V}$, and $\mathrm{Mn}$ ) at the octahedral and tetrahedral sites in the normal and inverse spinel structures. In many cases, the impurities introduce deeper bands into the host energy bandgap. An analysis of the symmetry and composition of these bands show that they have $t$ or $e$ symmetry. These bands are full, empty, or partially full. It increases the number of possible inter-band transitions and the possible application to optoelectronic devices. The substitutional spinel energies indicate that substitution by these impurities is favorable energetically. Thus, the insertions of intermediate states into the energy band gap using these impurities can potentiality improve the optoelectronic properties of the host spinel.

A further extension using the GGA $+\mathrm{U}$ method show that for the $\left(\mathrm{V}_{\mathrm{Mg}}\right)_{\mathrm{X}=0}$ and $\left(\mathrm{Cr}_{\mathrm{Mg}}\right)_{\mathrm{X}=0}$ substitutions the partially-full IB with GGA is split into an empty upper and a full lower Hubbard band. The $U$ effect is larger for the $\left(\mathrm{V}_{\mathrm{Mg}}\right)_{\mathrm{X}=0}$ substitution that for the $\left(\mathrm{Cr}_{\mathrm{Mg}}\right)_{\mathrm{X}=0}$ substitution.

\section{ACKNOWLEDGMENTS}

This work has been supported by the National Spanish projects Bibiana (PIB2010US-00096) and the European Commission through the funding of the project NGCPV (FP7-EU-JPN 283798), and by La Comunidad de Madrid through the funding of the project NUMANCIA-2 (Ref. N: S-2009/ENE-1477).

${ }^{1}$ P. Porta, A. Anichini, and U. Bucciarelli, J. Chem. Soc., Faraday Trans. 75, 1876-1887 (1979).

${ }^{2}$ O. Kulikova, L. Kulyuk, A. Siminel, and V. Tezlevan, in Abstracts of 4th Int. Conf. MSCMP, Chisinau (2008), p. 188.

${ }^{3}$ L. L. Kulyuk and V. E. Tezlevan, in Multinary Chalcogenides $I I-I_{2}-$ VI4, Chisinau, Stiinta (1990), p. 94 
${ }^{4}$ Proceedings of the 7th International Conference on Ternary and Multinary Compounds, edited by S. K. Deb and A. Zunger (MRS, Pittsburgh, 1987); Proceedings of the Adriatico Research Conference on High Temperature Superconductors, edited by S. Lundqvist, E. Tosatti, M. P. Tosi, and Yu Lu (World Scientific, Singapore, 1987).

${ }^{5}$ L. Gastaldi and A. Lapiccirella, J. Solid State Chem. 30, 223 (1979).

${ }^{6}$ A. Luque and A. Martí, Phys. Rev. Lett. 78, 5014 (1997).

${ }^{7}$ P. Hohenberg and W. Kohn, Phys. Rev. 136, B864-B871 (1964).

${ }^{8}$ R. Ramprasad, H. Zhu, P. Rinke, and M. Scheffler, Phys. Rev. Lett. 108, 066404 (2012).

${ }^{9}$ D. A. Drabold and S. Estreicher, Theory of Defects in Semiconductors (Springer, Berlin, Heidelberg, Germany, 2007).

${ }^{10}$ W. Kohn and L. J. Sham, Phys. Rev. 140, A1133-A1138 (1965).

${ }^{11}$ J. M. Soler, E. Artacho, J. D. Gale, A. García, J. Junquera, P. Ordejonand, and D. Sánchez-Portal, J. Phys.: Condens. Matter 14, 2745 (2002) and references therein.

${ }^{12}$ J. P. Perdew, K. Burke, and M. Ernzerhof, Phys. Rev. Lett. 77, 3865 (1996); J. P. Perdew and M. Ernzerhof, Phys. Rev. Lett. 78, 1396 (1997).

${ }^{13}$ N. Troullier and J. L. Martins, Phys. Rev. B 43, 1993 (1991).

${ }^{14}$ L. Kleinman and D. M. Bylander, Phys. Rev. Lett. 48, 1425 (1982); D. M. Bylander and L. Kleinman, Phys. Rev. B 41, 907 (1990).

${ }^{15}$ O. F. Sankey and D. J. Niklewski, Phys. Rev. B 40, 3979 (1989).

${ }^{16}$ V. I. Anisimov, J. Zaanen, and O. K. Andersen, Phys. Rev. B 44, 943 (1991); V. I. Anisimov, I. V. Solovyev, M. A. Korotin, M. T. Czyyk, and G. A. Sawatzky, Phys. Rev. B 48, 929 (1993).

${ }^{17}$ C. Tablero, J. Phys.: Condens. Matter 20, 325205 (2008).

${ }^{18}$ C. Tablero, J. Chem. Phys. 130, 054903 (2009).

${ }^{19}$ D. D. O'Regan, M. C. Payne, and A. A. Mostofi, Phys. Rev. B 83, 245124 (2011).

${ }^{20}$ M. Grisolía, P. Rozier, and M. Benoit, Phys. Rev. B 83, 165111 (2011).

${ }^{21}$ M. Marinelli, S. Baroni, and F. Meloni, Phys. Rev. B. 38, 8258 (1988).
${ }^{22}$ J. Ruiz-Fuertes, D. Errandonea, F. J. Manjón, D. Martínez-García, A. Segura, V. V. Ursaki, and I. M. Tiginyanu, J. Appl. Phys. 103, 063710 (2008).

${ }^{23}$ P. M. Sirimanne, N. Sonoyama, and T. Sakata, J. Solid State Chem. 154, 476 (2000).

${ }^{24}$ M. Wakaki, O. Shintani, T. Ogawa, and T. Arai, Proc. Int. Conf. Ternary \& Multinary Compounds, Tokyo, 1980, Jpn. J. Appl. Phys. 19 (Suppl. 19-3), 255 (1980).

${ }^{25}$ I. Aguilera, P. Palacios, K. Sánchez, and P. Wahnón, Phys. Rev. B 81, 075206 (2010).

${ }^{26}$ M. J. Lucero, I. Aguilera, C. V. Diaconu, P. Palacios, P. Wahnón, and G. E. Scuseria, Phys. Rev. B 83, 205128 (2011).

${ }^{27}$ F. Semari, R. Khenata, M. Rabah, A. Bouhemadou, S. Bin Omran, A. H. Reshak, and D. Rached, J. Solid State Chem. 183, 2818-2825 (2010).

${ }^{28}$ J. Tao, J. P. Perdew, V. N. Starovero, and G. E. Scuseria, Phys. Rev. Lett. 91, 146401 (2003).

${ }^{29}$ T. M. Henderson, A. F. Izmaylov, G. Scalmani, and G. E. Scuseria, J. Chem. Phys. 131, 044108 (2009).

${ }^{30}$ S.-H. Wei, L. G. Ferreira, J. E. Bernard, and A. Zunger, Phys. Rev. B 42, 9622 (1990).

${ }^{31}$ R. M. Martin, Electronic Structure (Cambridge Univ. Press, Cambridge, England, 2004).

${ }^{32} \mathrm{~K}$. Ohno, K. Esfarjani, and Y. Kawazoe, Computational Materials Science, From ab initio to Monte Carlo Methods (Springer, 1999).

${ }^{33}$ R. G. Parr and W. Yang, Density Functional Theory of Atoms and Molecules (Oxford, New York, 1989).

${ }^{34}$ J. F. Dobson, G. Vignale, and M. P. Das, Electron Density Functional Theory, Recent Progress and New Directions (Plenum Press, New York, 1998). 